\title{
Effect of Soft X-ray Irradiation on Film Properties of a Hydrogenated Si-Containing DLC Film
}

\author{
Kazuhiro Kanda ${ }^{1, *} \mathbb{D}$, Ryo Imai ${ }^{1}$, Shotaro Tanaka ${ }^{1}$, Shuto Suzuki ${ }^{1}$, Masahito Niibe ${ }^{1}$, Takayuki Hasegawa ${ }^{1}$, \\ Tsuneo Suzuki ${ }^{2}$ and Hiroki Akasaka ${ }^{3}$
}

1 Laboratory of Advanced Science and Technology for Industry, University of Hyogo, 3-1-2 Koto, Kamigori, Hyogo 678-1205, Japan; szp140@gmail.com (R.I.); shotnr@gmail.com (S.T.); chamomile0409@gmail.com (S.S.); niibe@lasti.u-hyogo.ac.jp (M.N.); t-hasegawa@kmtl.co.jp (T.H.)

2 Department of Nuclear System Safety Engineering, Nagaoka University of Technology, 1603-1 Kamitomioka-machi, Nagaoka, Niigata 940-2188, Japan; suzuki@vos.nagaokaut.ac.jp

3 Department of Mechanical Engineering, School of Engineering, Tokyo Institute of Technology, 2-12-1 Ookayama, Meguro-ku, Tokyo 152-8550, Japan; akasaka@mech.titech.ac.jp

* Correspondence: kanda@lasti.u-hyogo.ac.jp; Tel.: +81-791-58-0476

check for updates

Citation: Kanda, K.; Imai, R.; Tanaka, S.; Suzuki, S.; Niibe, M.; Hasegawa, T.; Suzuki, T.; Akasaka, H. Effect of Soft $\mathrm{X}$-ray Irradiation on Film Properties of a Hydrogenated Si-Containing DLC Film. Materials 2021, 14, 924. https://doi.org/10.3390/ma14040924

Academic Editor: Jordi Sort

Received: 27 November 2020

Accepted: 8 February 2021

Published: 15 February 2021

Publisher's Note: MDPI stays neutral with regard to jurisdictional claims in published maps and institutional affiliations.

Copyright: (c) 2021 by the authors. Licensee MDPI, Basel, Switzerland. This article is an open access article distributed under the terms and conditions of the Creative Commons Attribution (CC BY) license (https:// creativecommons.org/licenses/by/ $4.0 /)$.
Abstract: The effect of soft X-ray irradiation on hydrogenated silicon-containing diamond-like carbon (Si-DLC) films intended for outer space applications was investigated by using synchrotron radiation (SR). We found that the reduction in film thickness was about $60 \mathrm{~nm}$ after $1600 \mathrm{~mA} \cdot \mathrm{h}$ SR exposure, whereas there was little change in their elemental composition. The reduction in volume was attributable to photoetching caused by SR, unlike the desorption of hydrogen in the case of exposure of hydrogenated DLC (H-DLC) film to soft X-rays. The ratio of the $\mathrm{sp}^{2}$ hybridization carbon and $\mathrm{sp}^{3}$ hybridization carbon in the hydrogenated Si-DLC films, $\mathrm{sp}^{2} /\left(\mathrm{sp}^{2}+\mathrm{sp}^{3}\right)$ ratio, increased rapidly from $\sim 0.2$ to $\sim 0.5$ for SR doses of less than $20 \mathrm{~mA} \cdot \mathrm{h}$. SR exposure significantly changed the local structure of carbon atoms near the surface of the hydrogenated Si-DLC film. The rate of volume reduction in the irradiated hydrogenated Si-DLC film was 80 times less than that of the H-DLC film. Doping DLC film with $\mathrm{Si}$ thus suppresses the volume reduction caused by exposure to soft $\mathrm{X}$-rays.

Keywords: diamond-like carbon; Si containing diamond-like carbon film; soft X-ray; synchrotron radiation; $X$-ray reflectivity; elastic recoil detection analysis; Rutherford backscattering spectrometry; $\mathrm{X}$-ray photoelectron spectroscopy; near-edge X-ray absorption fine structure

\section{Introduction}

Amorphous carbon films consisting of mixtures of $\mathrm{sp}^{3}$ hybridization carbon and $\mathrm{sp}^{2}$ hybridization carbon are known as diamond-like carbon (DLC) films, and DLC films often contain a certain amount of hydrogen [1-3]. They have excellent properties such as high hardness, a low friction coefficient, high abrasion quality, a gas barrier, chemical inertness, and surface lubrication [4-10]. Thanks to these characteristics, DLC films have widespread applications in, for instance, automobile parts, magnetic storage disks, implant parts, and food containers. Expanded use of DLC films has led to studies on their properties. In particular, the last decade has seen the development of novel DLC films that include heterozygous elements, with the exception of carbon and hydrogen [11-15].

Recently, interest has grown in the use of DLC films for outer space applications [16]. In particular, actuators of satellites need lubricants, but the oil that is used in terrestrial applications is unsuitable for outer space because it freezes in a vacuum. DLC films, especially higher hydrogenated DLC (H-DLC) films which contain more than $40 \%$ hydrogen, maintain low friction in a vacuum and are regarded as potential solid lubricants in outer space [17-19]. The environmental factors in low earth orbit (LEO), which include ultra-high vacuums, soft $X$-rays, atomic oxygen $(\mathrm{AO})$, and sudden rises and falls in temperature, are very different from those on the ground. To use hydrogenated silicon-containing 
diamond-like carbon (Si-DLC) film safely in LEO, it is necessary to evaluate its tolerance to other environmental factors.

DLC films have been considered to be durable against X-ray exposure [20]. However, our group has studied the effect of irradiation of H-DLC films by soft $X$ rays and found that: (1) the volume of the H-DLC film is reduced under irradiation by soft X-rays; (2) the main reason for the volume reduction is desorption of hydrogen; and (3) new bonds between carbon atoms are formed by desorption of hydrogen, and the $\mathrm{sp}^{2} / \mathrm{sp}^{3}$ ratio of carbon in the film increases [21,22].

This study investigated irradiation of hydrogenated Si-DLC film by soft X-rays for the purpose of understanding tolerance of films to soft $X$-rays. Our main interest was in the variations in the volume and properties of the film and the mechanism of these variations. Thereby, we exposed hydrogenated Si-DLC film to soft X-rays using synchrotron radiation (SR) and measured the SR dose dependence of the film thickness, film density, elemental content inside and at the surface of the film, and the local structure of C and Si in the film. We examined the effect of soft X-rays on hydrogenated Si-DLC and the effect of the doping of DLC film with Si.

\section{Materials and Methods}

We paid special attention to the rate and the reaction process involved in the reduction in volume of the hydrogenated Si-DLC film due to irradiation. To investigate the effects of the soft X-ray irradiation inside and on the surface of the hydrogenated Si-DLC films and the influence of Si atoms on these effects, we exposed films to SR in the soft X-ray region in a dose region from 0 to $3000 \mathrm{~mA} \cdot \mathrm{h}$ and measured various film properties depending on the SR dose as follows: (1) Film thickness, from which the reduction in film volume could be estimated, was measured with a stylus profiler, SEM, and X-ray reflectivity (XRR); (2) Film density was estimated by taking X-ray reflection measurements; (3) The elemental composition of the hydrogenated Si-DLC film was evaluated by a combination of elastic recoil detection analysis (ERDA) and Rutherford backscattering spectrometry (RBS); (4) The surface composition of the hydrogenated Si-DLC film was observed by X-ray photoelectron spectroscopy (XPS); (5) The local structure of carbon and silicon atoms was analyzed on the basis of the $C K$ edge, $\mathrm{Si} K$ edge, and $\mathrm{Si} L$ edge near-edge $\mathrm{X}$-ray absorption fine structure (NEXAFS) spectra.

\subsection{Preparation of Samples and SR Irradiation Apparatus}

The hydrogenated Si-DLC film was deposited on a Si wafer by using an amplitudemodulated radio-frequency plasma-enhanced chemical vapor deposition method (Nippon ITF Co., Kyoto, Japan) [23]. This method enables DLC films containing a lot of hydrogen to be deposited. The desired thickness of the hydrogenated Si-DLC film was $500 \mathrm{~nm}$. The observed thickness of the as-deposited hydrogenated Si-DLC film was $522 \mathrm{~nm}$ using a scanning electron microscope (SEM).

\subsection{Irradiation of Soft X-rays}

The irradiation of the hydrogenated Si-DLC films by soft X-rays was carried out at Beamline 06 (BL06) of the NewSUBARU synchrotron facility of the University of Hyogo located in Kamigori of Japan [24,25]. Details on the experimental apparatus at BL06 have been described in previous reports [26,27]. In brief, the SR extracted from a bending magnet, which is the light source of BL06, was shaped into a straight beam via a pair of mirrors that was incident on the irradiation point. The SR irradiated the sample surface perpendicularly. The SR at the irradiation point had a continuous spectrum from the infrared to soft X-ray region (less than $1 \mathrm{keV}$ ). This energy range included $110 \mathrm{eV}$ and $300 \mathrm{eV}$, which are the ionization energies of the silicon $L$ shell and carbon $K$ shell, respectively. The penetration depth of $300 \mathrm{eV}$ X-rays was estimated to be 200-300 nm in the DLC film. During the experiment, the electron energy of the NewSUBARU ring was $1.0 \mathrm{GeV}$ and the ring current was kept at $300 \mathrm{~mA}$ in the top-up mode. The SR dose $(\mathrm{mA} \cdot \mathrm{h})$ was computed as the product 
of the ring current (mA) and exposure time (h). The hydrogenated Si-DLC film of the sample was fixed to an anoxic copper sample holder and placed at the irradiation point in the irradiation chamber. The temperature of the sample holder was measured using a thermocouple. During the exposure of the hydrogenated Si-DLC films to the soft X-rays, the pressure in the irradiation chamber was on the order of $10^{-5} \mathrm{~Pa}$ and the sample holder was confirmed to be at room temperature. In addition, the temperature of the sample holder could be raised to $150{ }^{\circ} \mathrm{C}$ by using a heater. After the exposure to SR, the irradiated hydrogenated Si-DLC films were stored in a dry box.

\subsection{Evaluation of the Reduction in Film Thickness}

We measured the film thickness with a stylus profiler to investigate the volume change of the hydrogenated Si-DLC film due to SR irradiation. For this measurement, the hydrogenated Si-DLC films were exposed to SR through an Au mesh mask (wire diameter $0.07 \mathrm{~mm} \mathrm{R}, 100 \mathrm{mesh} / \mathrm{inch}$ ). The step depth was estimated with the stylus profiler (Bruker, DEKTAK 6M, Billerica, MA, USA), which measured the difference in altitude between the area exposed to SR and the area shadowed by the mesh.

To verify the step-depth measurements, we measured the film thickness by using two other methods, i.e., by observing section images of the hydrogenated Si-DLC films using SEM (JEOL, JSM-6700F, Akishima, Japan) and by estimating the film thickness from the $X$-ray reflectivity (XRR). The XRR measurement is described in the next section. In both methods, the reduction in film thickness was estimated by subtracting the film thickness after SR irradiation from that of the as-deposited film (522 $\mathrm{nm})$.

\subsection{X-ray Reflection Measurements}

We estimated the densities of the hydrogenated Si-DLC films from the XRR measurements by using an X-ray diffractometer (Phillips, X'Pert PRO MRD, Amsterdam, Nederland). X-ray reflectivity was measured in the range of an incident angle, $2 \theta$, from $0.1^{\circ}$ to $1.0^{\circ}$ by a step of $0.003^{\circ}$ by using $\mathrm{Cu} \mathrm{K} \alpha$ as the $\mathrm{X}$-ray source.

\subsection{Measurements Elastic Recoil Detection Analysis and Rutherford Backscattering Spectrometry}

The elemental composition of hydrogenated Si-DLC films was determined by a combination of ERDA and RBS measurements using the electrostatic accelerator (Nisshin High Voltage, NT-1700HS, Kyoto, Japan) at the Extreme Energy-Density Research Institute, Nagaoka University of Technology. The experimental RBS/ERDA apparatus is described in detail in [28-31]. Briefly, $\mathrm{He}^{+}$ions accelerated to $2.5 \mathrm{MeV}$ using a tandem Pelletron accelerator (High Voltage Engineering Europa, Amsterdam, Nederland) were used as the incident beam, for which the angle with respect to the surface normal was $72^{\circ}$. In the RBS experiments, recoil $\mathrm{He}^{+}$ions were detected using a solid-state detector (SSD) (Ortec, Ortec ULTRA, Oak Ridge, TN, USA), for which the angle with respect to the surface normal was $78^{\circ}$. In the ERDA experiments, hydrogen atoms scattered by $\mathrm{He}^{+}$ions were detected using another SSD, for which the angle with respect to the surface normal was $12^{\circ}$. The observed RBS/ERDA spectra were simulated by a 1\% step; therefore, the obtained error of the composition of each element was $1 \%$.

\subsection{X-ray Photoelectron Spectroscopy Measurements}

We estimated the elemental composition of the hydrogenated Si-DLC film surface by using a conventional X-ray photoelectron spectroscopy (XPS) apparatus (Shimadzu, ESCA-1000, Kyoto, Japan). The Mg K $\alpha$ line was used as the X-ray source, and the incident angle was $45^{\circ}$. The detection depth of XPS using the $\mathrm{Mg} \mathrm{K} \alpha$ line $(1253.6 \mathrm{eV})$ was estimated to be less than $3 \mathrm{~nm}$ from the surface from the escape depth of photoelectrons.

\subsection{Measurements of Near-Edge X-ray Absorption Fine Structure}

NEXAFS spectroscopy using synchrotron radiation is sensitive to the local structure around the absorber atom $[32,33]$. To discuss the variations in the local structure of the 
hydrogenated Si-DLC film due to exposure to SR, the C K edge, Si $K$ edge, and Si $L$ edge NEXAFS spectra were measured. The $C K$ edge and $S i L$ edge measurements were performed at BL09A in the NewSUBARU synchrotron facility, which has an 11-m-undulator as a light source and a grating monochromator $[34,35]$. The NEXAFS spectra of the $C K$ edge absorption and Si $L$ edge absorption were measured using a grating of 1200 and 900 grooves/mm in the ranges $275-330 \mathrm{eV}$ and $100-125 \mathrm{eV}$, respectively. The energy resolution was estimated to be less than $0.5 \mathrm{eV}$ (FWHM). The NEXAFS measurement of the Si $K$ absorption was performed at BL05A of the NewSUBARU synchrotron facility, which has a bending magnet as a light source and a double crystal monochromator [36]. The NEXAFS spectra of the Si K edge absorption were measured in the range 1810-1890 eV using $\operatorname{InSb}(111)$. The energy resolution was estimated to be less than $2.0 \mathrm{eV}$ (FWHM). In the measurement at both beamlines, the irradiation angle at the sample was the "magic angle" of $54.7^{\circ}$ with respect to the surface. The electrons coming from the sample were detected in total electron yield (TEY) mode. The intensity of the incident photon beams $\left(\mathrm{I}_{0}\right)$ was measured by monitoring the photocurrent from a gold mesh. The absorption signal was given by the ratio between the out-coming electron intensity from the sample, $\mathrm{I}_{\mathrm{s}}$, and $\mathrm{I}_{0}$. The detection depth of the NEXAFS measurement in TEY mode was reported to be about $4 \mathrm{~nm}$ at the $\mathrm{N} K$ edge of $409 \mathrm{eV}$ [37].

\section{Results}

\subsection{Reduction in Thickness of Hydrogenated Si-DLC Film}

The reduction of the film volume is undoubtedly important for the utilization of the hydrogenated Si-DLC film. As mentioned in Section 2.3, we observed the change in film thickness in three different ways. Examples of cross-sectional observation of the hydrogenated Si-DLC films by SEM are shown in Figure 1.

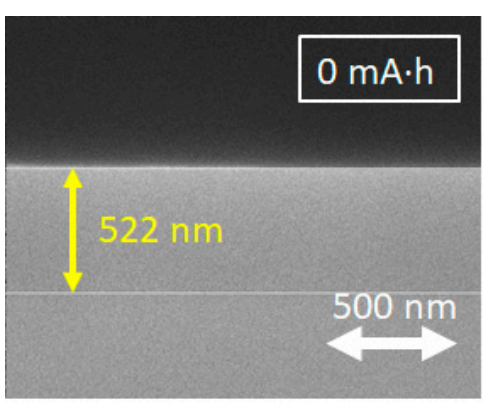

a)

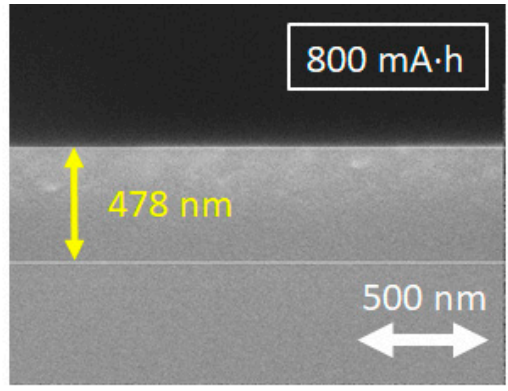

b)

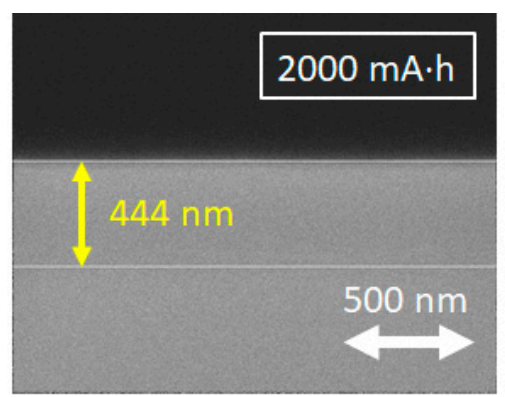

c)

Figure 1. Cross-section of the hydrogenated silicon-containing diamond-like carbon (Si-DLC) films (a) before irradiation, and after irradiation of (b) $800 \mathrm{~mA} \cdot \mathrm{h}$ and (c) $2000 \mathrm{~mA} \cdot \mathrm{h}$, observed using SEM.

The SR dose dependence of the decrease in thickness of the hydrogenated Si-DLC film is depicted in Figure 2. The blue circles show the reduction in thicknesses measured using the stylus profiler. The green and brown squares show the reduction in thicknesses estimated from the section images of films before and after SR irradiation and from XRR, respectively. The reduction estimated by the stylus profiler was in good accordance with those estimated from the SEM and XRR measurements. The reduction gradually reached about $60 \mathrm{~nm}$ after $2000 \mathrm{~mA} \cdot \mathrm{h}$ of SR exposure. It remained constant at doses greater than $2000 \mathrm{~mA} \cdot \mathrm{h}$. These results show that by doping H-DLC with Si, the effect of SR radiation was lower, and only at higher X-ray doses did the effect become comparable for the two kinds of materials.

In addition, we exposed the hydrogenated Si-DLC film to SR while keeping the substrate temperature at $100{ }^{\circ} \mathrm{C}$ by using a heating system. The red circles show the reduction in film thickness measured using the stylus profiler when the substrate was heated. The rate of reduction did not change when the substrate temperature rose. This result, in which 
reaction rate did not depend on the substrate temperature, indicates that the reduction in film thickness does not proceed via a process ruled by activation energy.

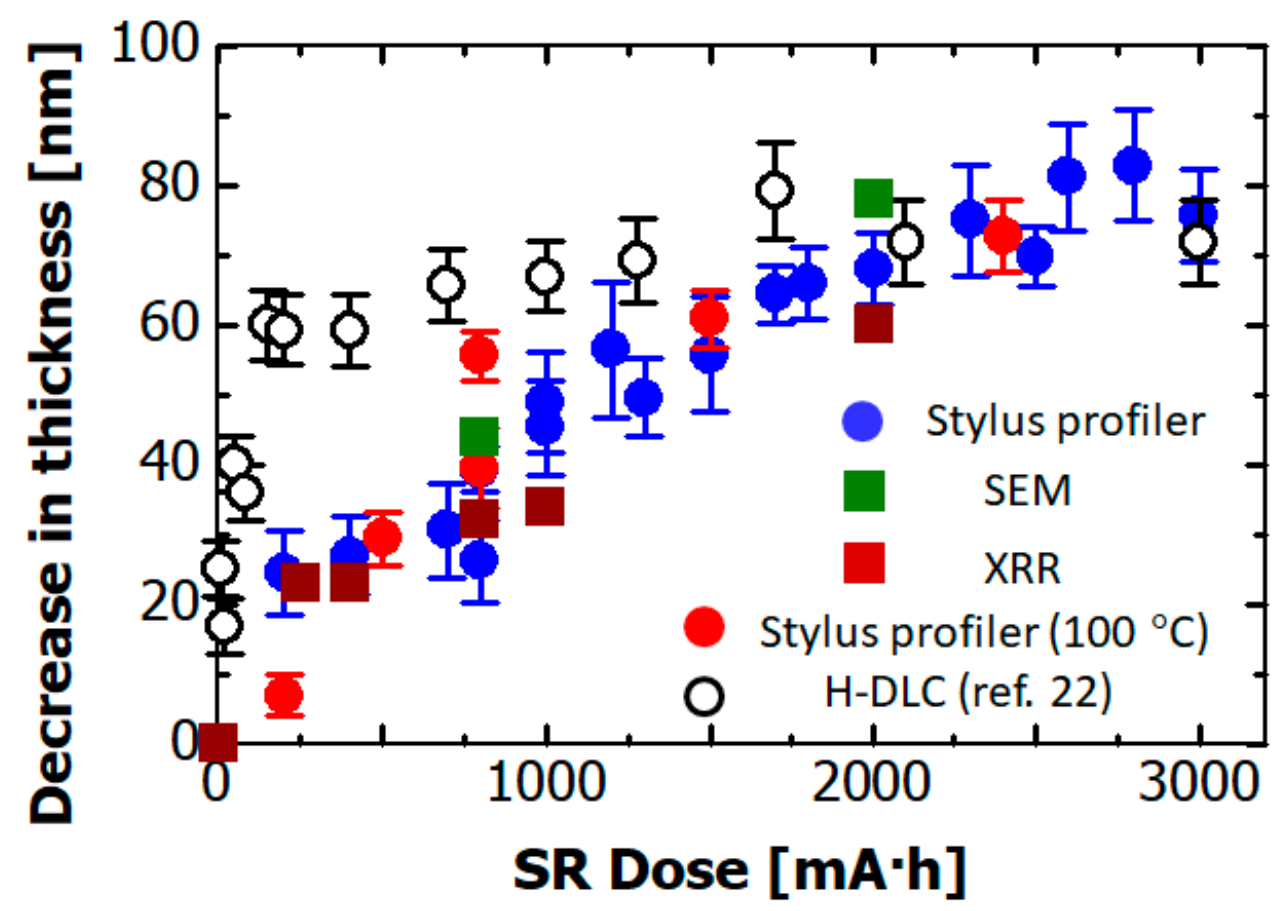

Figure 2. Synchrotron radiation (SR) dose dependence of the reduction in film thickness of the hydrogenated Si-DLC film measured with a stylus profiler (blue circles), SEM (green squares), and X-ray reflectivity (XRR, brown squares). Red circles indicate reductions in film thickness acquired by the stylus profiler in case of substrate heated to $100{ }^{\circ} \mathrm{C}$ with a heating system. Open circles indicate reductions in the film thickness of non-doped hydrogenated DLC (H-DLC) film after SR exposure [22].

The open circles show the reduction in film thickness of H-DLC film (in which no element was doped) due to SR exposure, the values of which were converted from the film thicknesses reported in Reference [22]. The reduction in film thickness was about $60 \mathrm{~nm}$ after $20 \mathrm{~mA} \cdot \mathrm{h}$ SR exposure. On the other hand, in the case of SR irradiation of the hydrogenated Si-DLC film, a dose of $1600 \mathrm{~mA} \cdot \mathrm{h}$ was needed to cause a reduction in film thickness of $60 \mathrm{~nm}$. Namely, the rate of reduction in volume was 80 times lower that of the non-doped hydrogenated DLC film. As a result, it was found that doping hydrogenated DLC film with Si reduced the rate of reduction in film thickness due to SR exposure.

\subsection{Film Density}

Film density is an important index to distinguish the volume change of film due to photoetching or shrinkage. Since it is thought that these densities have a distribution in the thickness direction, there were some samples that could not completely satisfy the fitting, especially at an angle slightly higher than the critical angle. Some samples also could not be completely fitted by single Si-DLC layer model. Therefore, profiles of Si-DLC films were fitted by a one-layer model as much as possible around the critical angle. Figure 3 shows the XRR profiles and fitting results. XRR analyses were performed using $X^{\prime}$ Pert Reflectivity software (Phillips, Amsterdam, Nederland).

Figure 4 shows the film density dependence on SR dose obtained from the XRR measurements. The value in this figure describe the density of the thickest layer of these layers. The density of the hydrogenated Si-DLC film before irradiation was $\sim 1.5 \mathrm{~g} / \mathrm{cm}^{3}$. It markedly increased to $\sim 1.65 \mathrm{~g} / \mathrm{cm}^{3}$ after $500 \mathrm{~mA} \cdot \mathrm{h}$ of SR exposure, and remained constant at $1.65 \mathrm{~g} / \mathrm{cm}^{3}$ at doses of more than $500 \mathrm{~mA} \cdot \mathrm{h}$. These results indicate that the increase in film density caused by the SR exposure ceased at a small SR dose within $500 \mathrm{~mA} \cdot \mathrm{h}$, 
which is different from the case of irradiation of non-doped H-DLC film by soft X-rays, where the film density increased after more than $1500 \mathrm{~mA} \cdot \mathrm{h}$ of SR exposure [22].

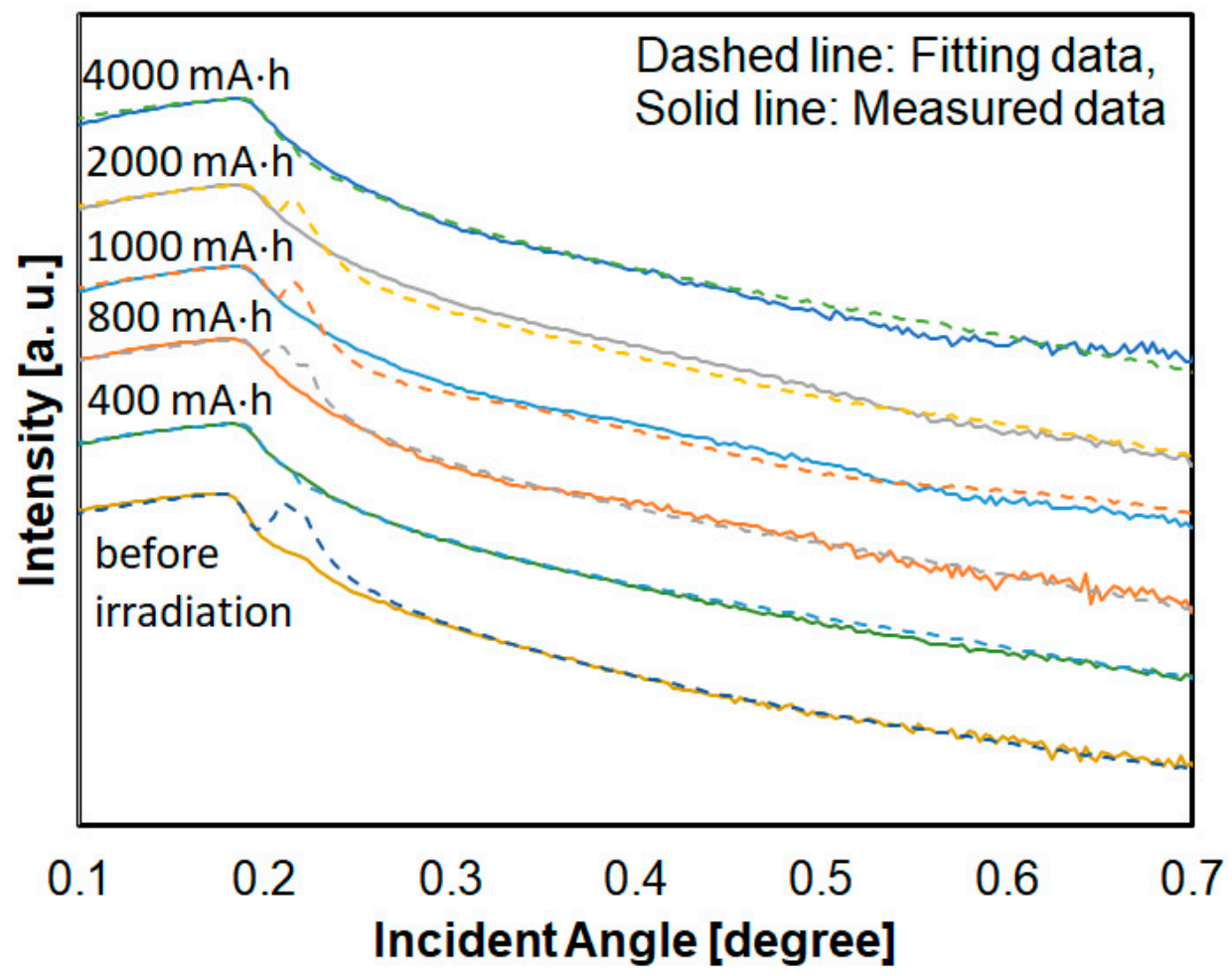

Figure 3. XRR profiles and fitting results of hydrogenated Si-DLC film.

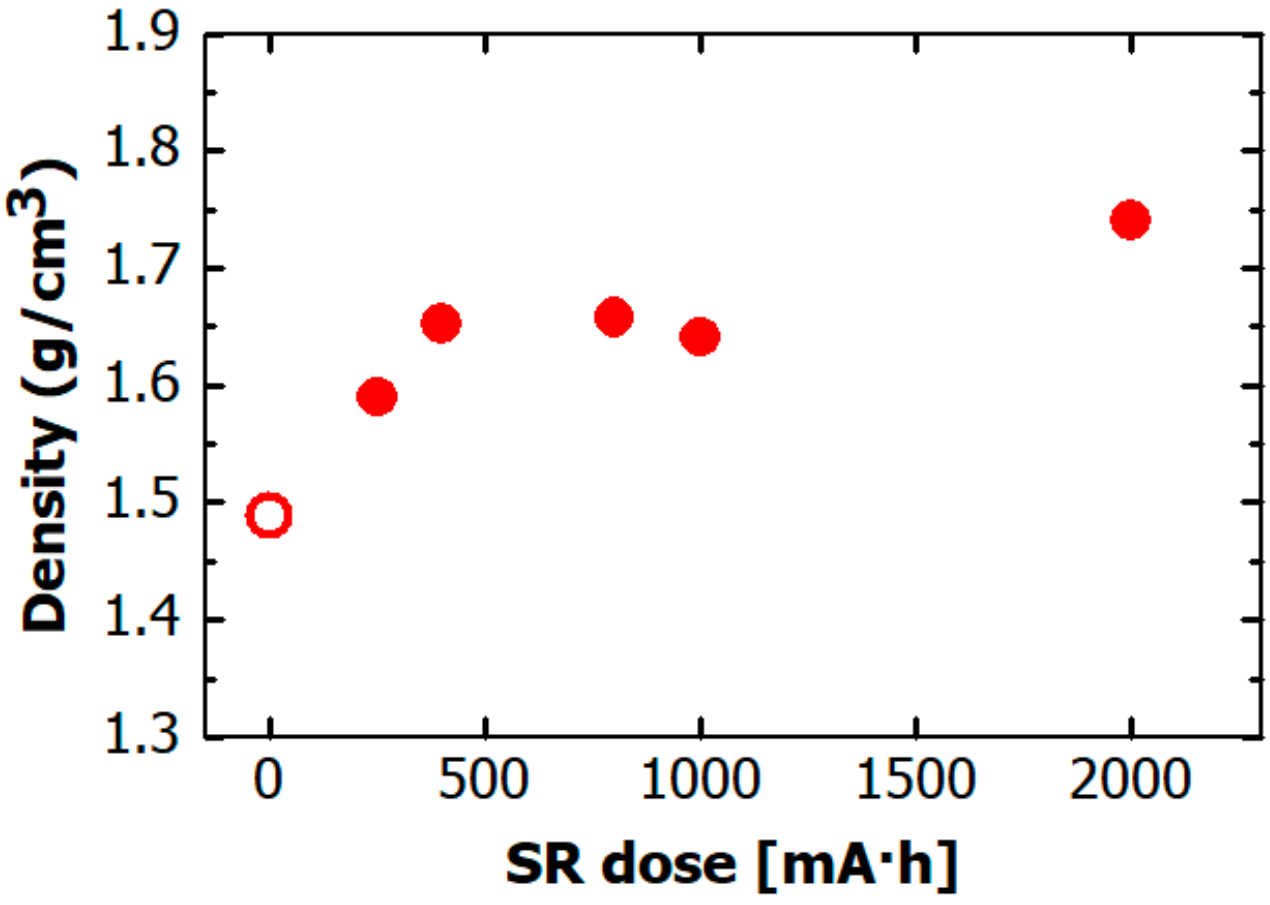

Figure 4. Dependence on SR dose of density of hydrogenated Si-DLC film. The open circle indicates density of hydrogenated Si-DLC film before SR irradiation. 


\subsection{Elemental Composition of Hydrogenated Si-DLC Film}

As described in the introduction, the exposure to SR causes the volume of the $\mathrm{H}$ DLC film to shrink because of the desorption of hydrogen [21,22]. Therefore, the dose dependence of the hydrogen content is the most notable factor when discussing the effect of SR on hydrogenated Si-DLC films. The elemental composition of hydrogenated Si-DLC films was determined by a combination of RBS and ERDA measurements. The RBS and ERDA profiles of Si-DLC films before irradiation of SR (Figure 5a) and after irradiation of $2000 \mathrm{~mA} \cdot \mathrm{h}$ (Figure $5 \mathrm{~b}$ ) are shown as representative examples.

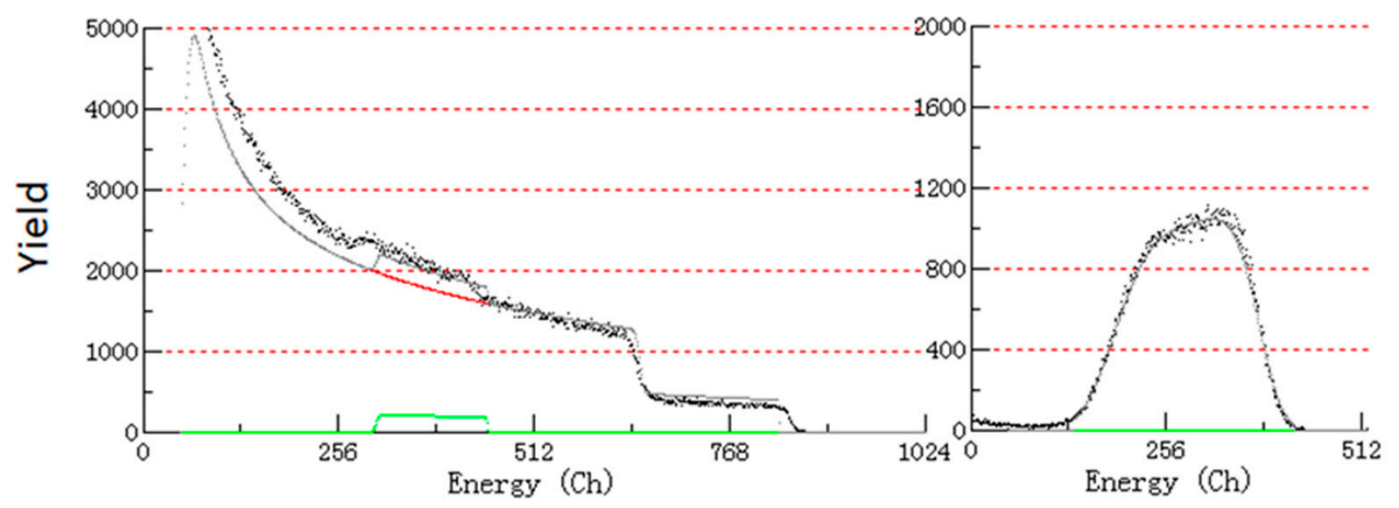

a) before irradiation

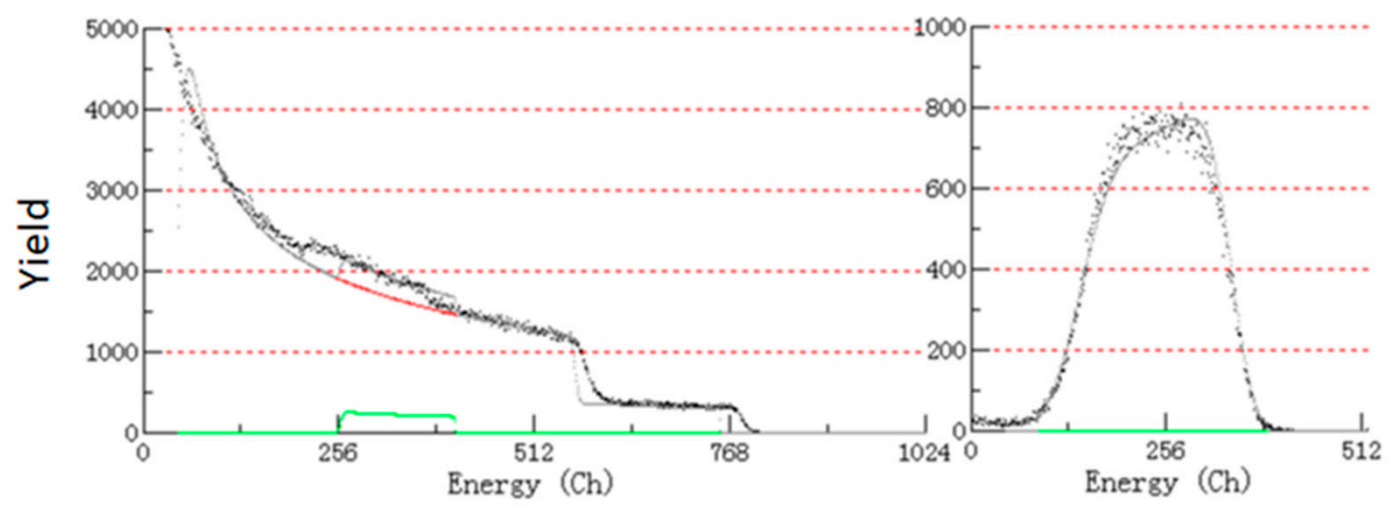

b) after irradiation of $2000 \mathrm{~mA} \cdot \mathrm{h}$

Figure 5. Rutherford backscattering spectrometry (RBS) profile (left side) and elastic recoil detection analysis (ERDA) profile (right side) of (a) Si-DLC film before irradiation and (b) Si-DLC film after irradiation of $2000 \mathrm{~mA} \cdot \mathrm{h}$.

The dose dependences of the hydrogen and silicon composition ratios in the hydrogenated Si-DLC films are shown in Figure 6 . The atomic ratios were $\sim 0.4$ for hydrogen and $\sim 0.2$ for silicon before the SR irradiation (open circles in the figure). Other elements were not found in the RBS spectrum. Moreover, the hydrogen and silicon composition ratios did not change after SR exposure. This result means that desorption of hydrogen from the hydrogenated Si-DLC film was not caused by the exposure to soft X-rays. Namely, doping the DLC film with Si helps to suppress desorption of hydrogen from film. 


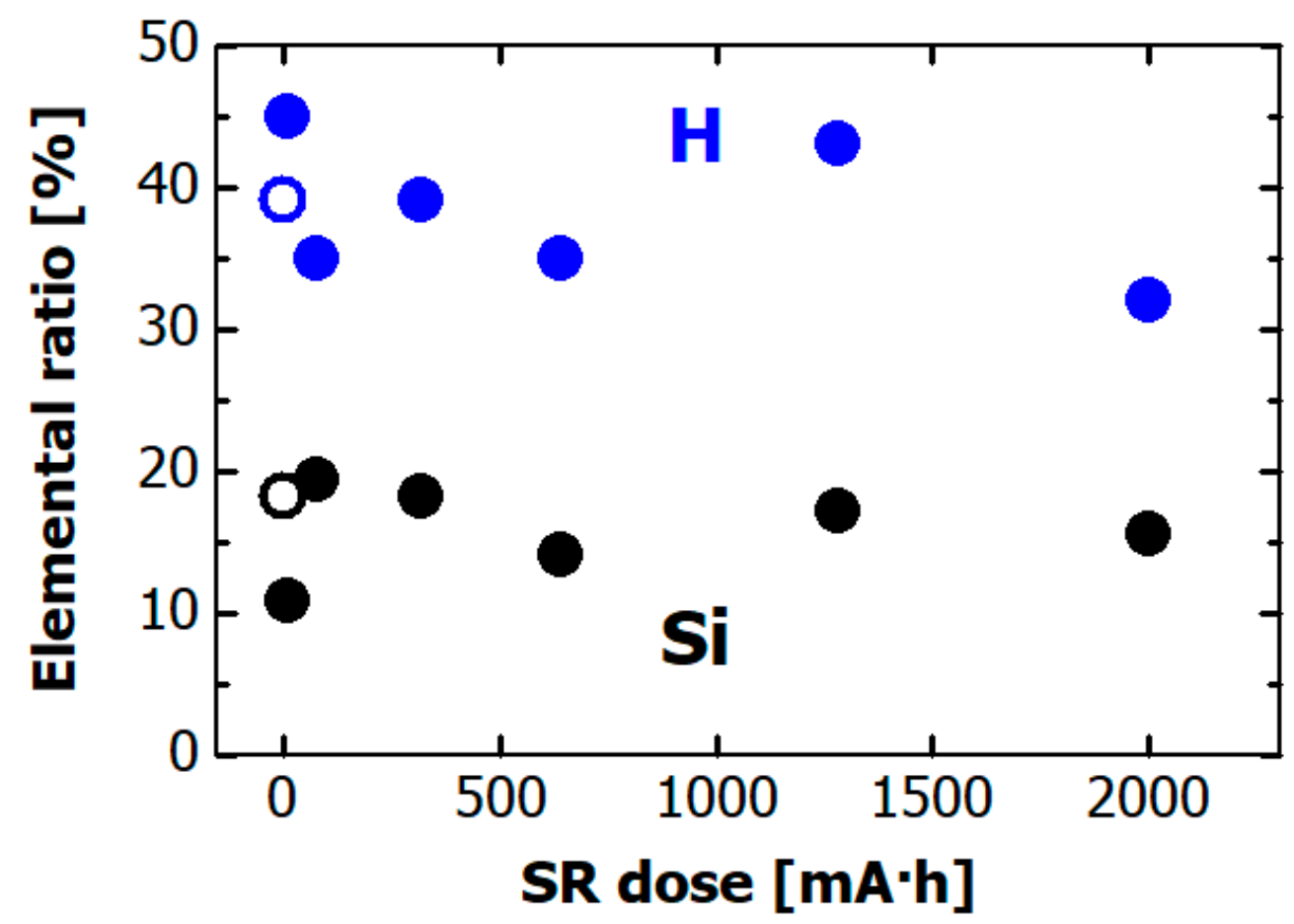

Figure 6. Dependence on SR dose of elemental composition ratio in hydrogenated Si-DLC film, as estimated by ERDA and RBS. Blue and black circles respectively indicate hydrogen and silicon ratios. The open circle indicates hydrogen and silicon ratios before the SR irradiation.

3.4. Elemental Composition and Chemical State of Hydrogenated Si-DLC Film Surface Acquired by $X$-ray Photoelectron Spectroscopy

Surface modification by exposure to soft X-rays often changes the elemental composition of the surface due to selective photon-stimulated desorption and/or surface oxidation. Figure 7 shows the dependence of XPS spectra of hydrogenated Si-DLC films on SR dose.

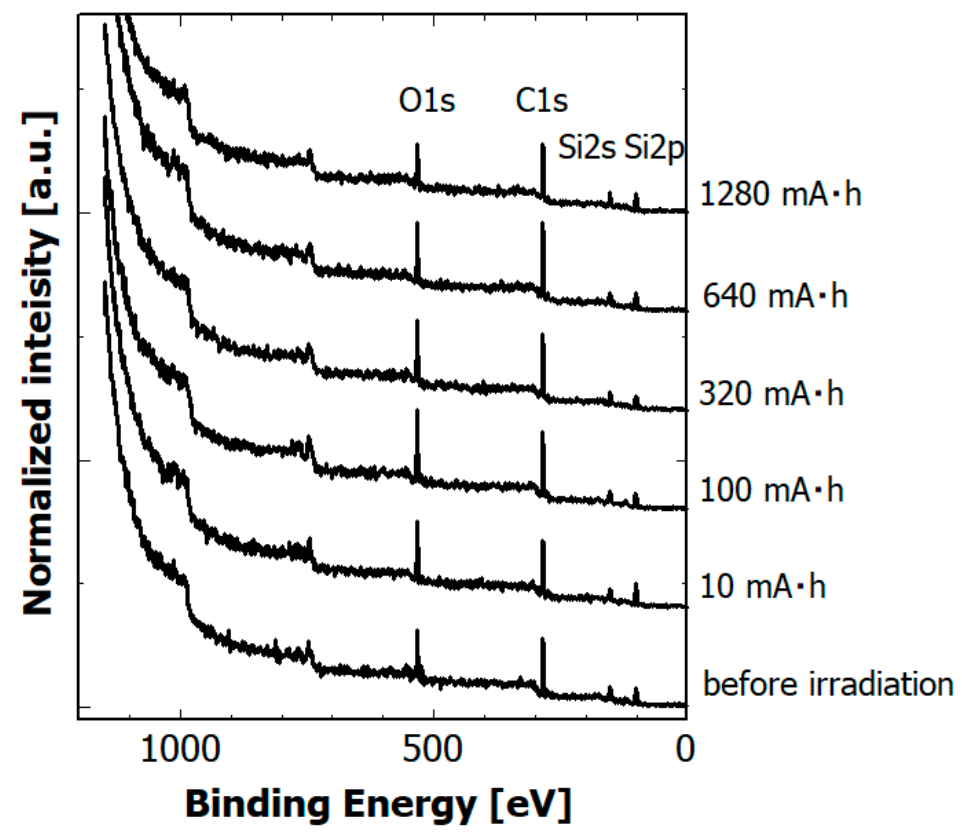

Figure 7. Dependence of XPS spectra of hydrogenated Si-DLC films on SR dose.

The dose dependences of the atomic composition of the hydrogenated Si-DLC film surface are plotted in Figure 8. The black, green, and red circles respectively show silicon, 
carbon, and oxygen content. The silicon, carbon, and oxygen contents before irradiation (open symbols in the figure) were $\sim 0.4, \sim 0.4$, and $\sim 0.2$, respectively. The observed oxygen is ascribable to surface oxidation rather than contamination during the film deposition because oxygen was not observed in the RBS spectra. Other elements were not found in the XPS spectrum before nor after SR irradiation. The atomic composition of the film surface was not changed after the SR exposure. Note that hydrogen content could not be measured in this XPS measurement.

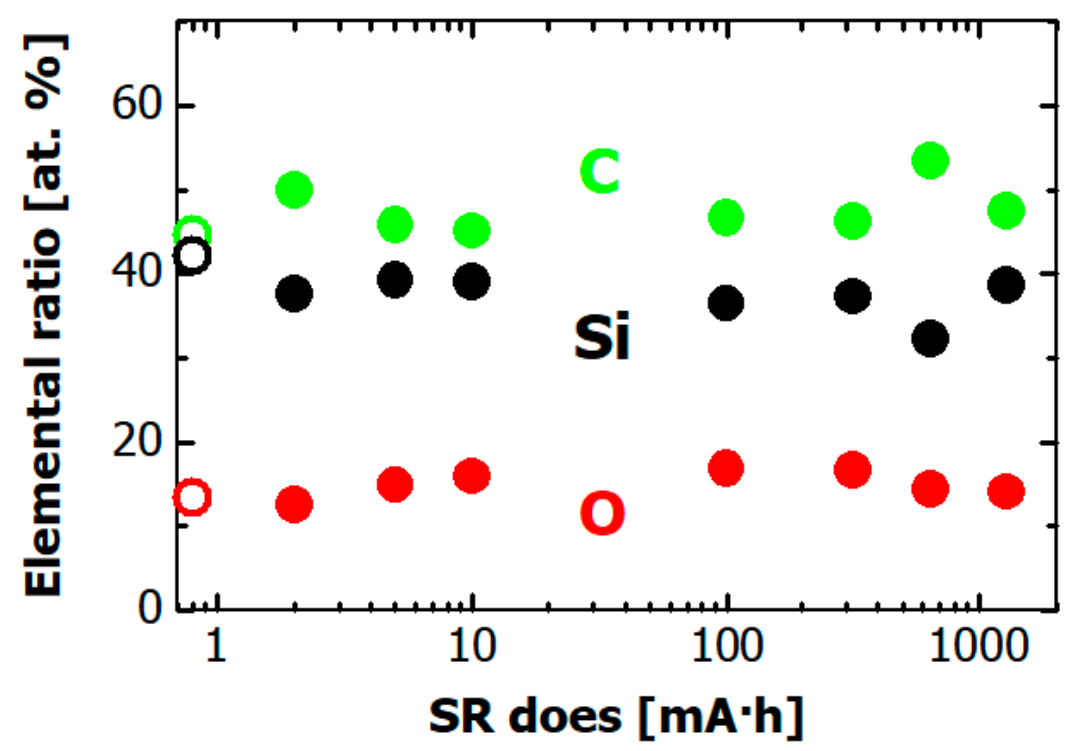

Figure 8. Dependence on SR dose of the elemental ratio of hydrogenated Si-DLC film surface as measured by XPS. Black, green, and red circles respectively show silicon, carbon, and oxygen contents. The open circles indicate carbon, silicon, and oxygen contents before the SR irradiation.

\subsection{Local Structure of Carbon and Silicon Atoms in Hydrogenated Si-DLC Film}

The C K edge NEXAFS spectra of the hydrogenated Si-DLC film before and after SR irradiation are depicted in Figure 9 together with those of $\beta$-SiC powder and typical commercial DLC film. The commercial film was deposited on 200-nm-thick Si wafers using the ion plating method, referred to as IP-DLC film hereafter. The IP-DLC film consisted of only carbon and hydrogen without silicon or other hetero-elements. The hydrogen content of the IP-DLC film was estimated to be $\sim 20 \%$ from a combination of ERDA and RBS measurements.

The sharp $\pi^{*}$ peak observed at $285.4 \mathrm{eV}$ is ascribed to the $\mathrm{C} 1 \mathrm{~s} \rightarrow \pi^{*}$ resonance transition originating from the carbon-carbon double bond. The broad $\sigma^{*}$ peak observed at about $285-310 \mathrm{eV}$ is ascribed to the $\mathrm{C} 1 \mathrm{~s} \rightarrow \sigma^{*}$ resonance transition [38]. The $\mathrm{C} K$ edge NEXAFS spectra of the Si-DLC films were classified into four types according to silicon content [39]. The C K edge NEXAFS spectra of the hydrogenated Si-DLC films before SR irradiation were classified as type 3 reported in Reference [39]. That is, the $\sigma^{*}$ peak was narrower than that of typical DLC film and shifted to the lower energy of $\sim 5 \mathrm{eV}$ due to the influence of the peak at $289 \mathrm{eV}$ derived from the $1 \mathrm{~s} \rightarrow \sigma^{*}(\mathrm{C}-\mathrm{Si})$ transition. In addition, the peak intensity of the $1 \mathrm{~s} \rightarrow \pi^{*}$ transition at $285.4 \mathrm{eV}$ was weak.

The features of the C K edge NEXAFS spectra of hydrogenated Si-DLC film greatly varied between before and after irradiation by soft $X$-rays. The peak intensity of the $1 \mathrm{~s} \rightarrow \pi^{*}$ transition at $285.4 \mathrm{eV}$ increased with an SR dose of $15 \mathrm{~mA} \cdot \mathrm{h}$, and it increased gently with an SR dose greater than $15 \mathrm{~mA} \cdot \mathrm{h}$. The $\sigma^{*}$ peak became broader and the intensity peak shifted to a higher energy. In other words, the $C K$ edge NEXAFS spectra of the hydrogenated Si-DLC films changed from type 3 to type 1 or 2 . As a result, the spectral features of the hydrogenated Si-DLC film after SR exposure of more than $320 \mathrm{~mA} \cdot \mathrm{h}$ resembled those of typical DLC film consisting only of carbon and hydrogen without silicon. 


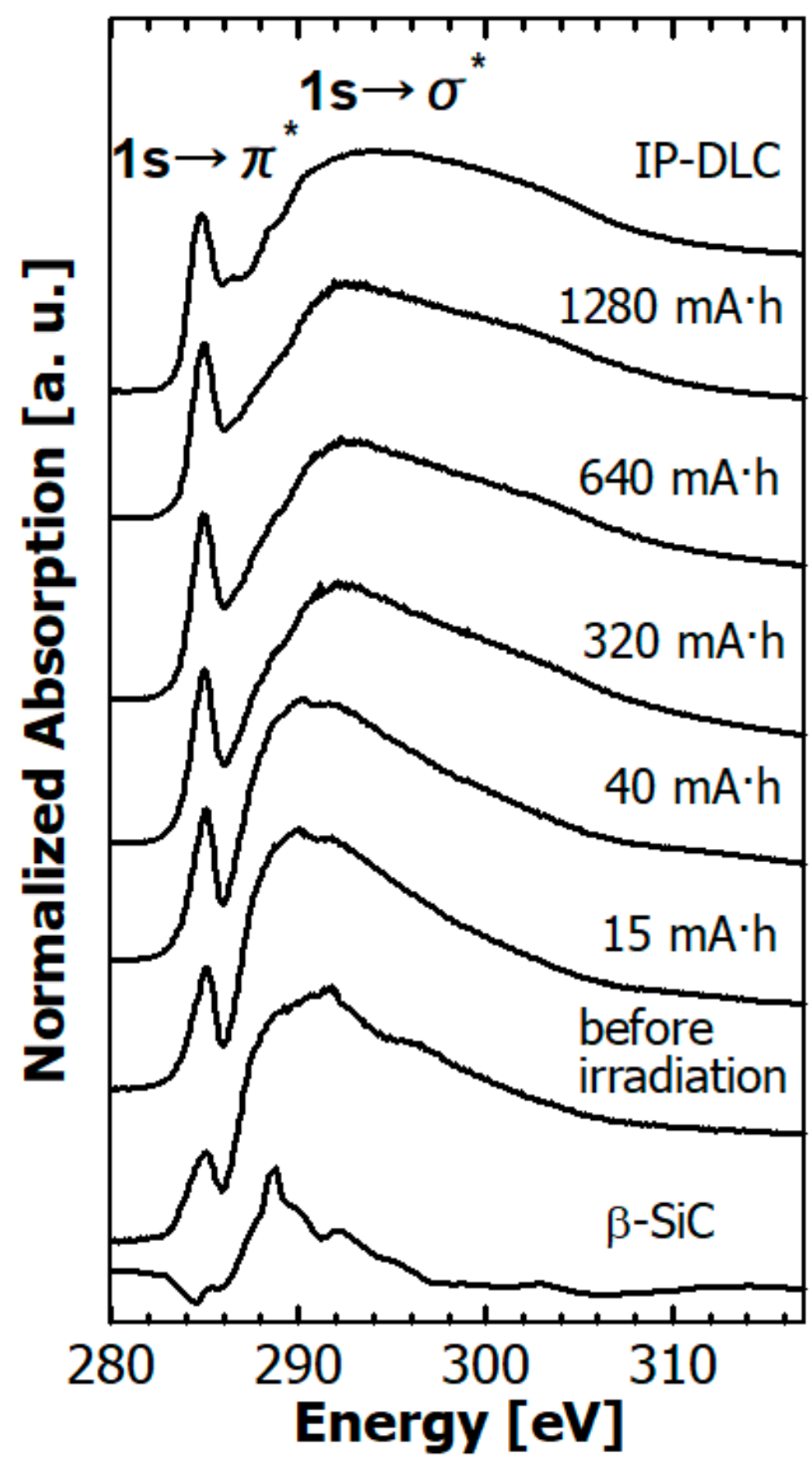

Figure 9. Dependence of the $C K$ edge near-edge $X$-ray absorption fine structure (NEXAFS) spectra of hydrogenated Si-DLC films on SR dose, together with those of $\beta$-SiC powder and IP-DLC film.

The $\mathrm{C}$ atoms in the DLC films consist of $\mathrm{sp}^{2}$ hybridization carbon and $\mathrm{sp}^{3}$ hybridization carbon. The $\mathrm{sp}^{2} / \mathrm{sp}^{3}$ ratio is considered to be a structural parameter that characterizes DLC film properties $[3,40]$. The absolute $\mathrm{sp}^{2} /\left(\mathrm{sp}^{2}+\mathrm{sp}^{3}\right)$ ratio of carbon atoms in the DLC film can be accurately determined from the C K edge NEXAFS spectra, as described in Refs. [41-43]. The SR dose dependence of the $\mathrm{sp}^{2} /\left(\mathrm{sp}^{2}+\mathrm{sp}^{3}\right)$ ratio in the hydrogenated Si-DLC film is plotted in Figure 10. The amount of $\mathrm{sp}^{2}$ bonded carbon atoms can be determined by normalizing the area of the resonance corresponding to the $1 \mathrm{~s} \rightarrow \pi^{*}$ transitions at $285.4 \mathrm{eV}$ with a large section of the spectrum. The absolute $\mathrm{sp}^{2} /\left(\mathrm{sp}^{2}+\mathrm{sp}^{3}\right)$ ratio was determined by comparing the normalized $1 \mathrm{~s} \rightarrow \pi^{*}$ area from the sample with that from the NEXAFS spectrum of highly ordered pyrolytic graphite (HOPG) as a standard sample. 
The $\mathrm{sp}^{2} /\left(\mathrm{sp}^{2}+\mathrm{sp}^{3}\right)$ ratio of the hydrogenated Si-DLC film before irradiation (open circle) was $\sim 0.23$, which indicated that $\mathrm{sp}^{3}$ hybridized carbon was a major component of the hydrogenated Si-DLC film. The $\mathrm{sp}^{2} /\left(\mathrm{sp}^{2}+\mathrm{sp}^{3}\right)$ ratio increased rapidly to $\sim 0.5$ for SR doses less than $20 \mathrm{~mA} \cdot \mathrm{h}$. At doses of more than $20 \mathrm{~mA} \cdot \mathrm{h}$, the $\mathrm{sp}^{2} /\left(\mathrm{sp}^{2}+\mathrm{sp}^{3}\right)$ ratio remained approximately constant at $\sim 0.5$.

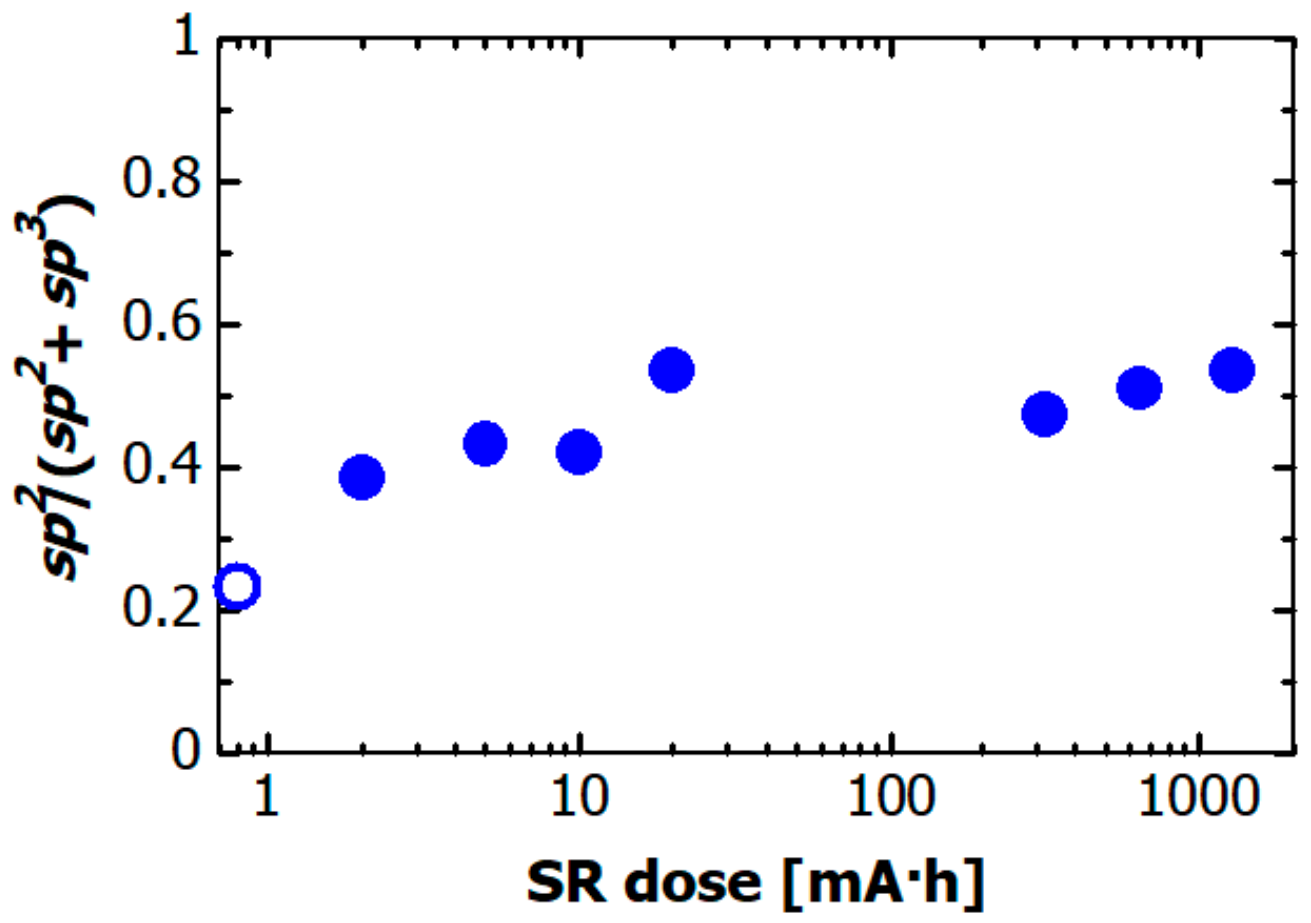

Figure 10. Dependence of the $\mathrm{sp}^{2} /\left(\mathrm{sp}^{2}+\mathrm{sp}^{3}\right)$ ratio in hydrogenated Si-DLC film on the SR dose. The open circle indicates $\mathrm{sp}^{2} /\left(\mathrm{sp}^{2}+\mathrm{sp}^{3}\right)$ ratio of hydrogenated Si-DLC film before SR irradiation.

The Si K edge NEXAFS spectra of the hydrogenated Si-DLC film before after irradiation are depicted in Figure 11 together those of reference materials, $\mathrm{SiO}_{2}$ powder, $\mathrm{Si}$ wafer, $\beta-\mathrm{SiC}$ powder, and amorphous hydrogenated silicon (a-Si:H) film. In the spectra of the $\mathrm{Si}$ wafer and a-Si:H film, peaks from $\mathrm{SiO}_{2}$ due to native oxidation were observed at $1846.8 \mathrm{eV}$ [44]. Si atoms in the hydrogenated Si-DLC film can be expected to have $\mathrm{Si}$, $\mathrm{C}, \mathrm{H}$, and / or $\mathrm{O}$ as neighboring atoms. The chemical environment around the absorbing atom can be evaluated from the positions of the absorption edge and the white line in the NEXAFS spectrum. The Si K edge shifts towards the higher energy side with increasing positive charge on the Si atom $[45,46]$. The edge from the hydrogenated Si-DLC film before irradiation was at $\sim 1840 \mathrm{eV}$, i.e., near that of the $\mathrm{Si}$ wafer and a-Si:H film. The white line was observed at about $3 \mathrm{eV}$ above the absorption edge, which resembled that of the $\mathrm{Si}$ wafer and a-Si:H film. These results indicate that the chemical environment of Si atoms in the hydrogenated Si-DLC film was similar to that in the Si wafer and a-Si:H film. After SR irradiation, a peak at $1846.8 \mathrm{eV}$, which was derived from $\mathrm{SiO}_{2}$, appeared in the NEXAFS spectra of the Si-DLC films. The intensity reached a maximum at $800 \mathrm{~mA} \cdot \mathrm{h}$ and decreased beyond $1000 \mathrm{~mA} \cdot \mathrm{h}$. On the other hand, the intensity increased in the energy range of about $1843-1846 \mathrm{eV}$. The peak in this energy range was reported to be due to deoxidization of $\mathrm{SiO}_{2}$ [45]. These results mean that an oxidized $\mathrm{Si}$ layer was generated at the surface of the hydrogenated Si-DLC film by oxidation of surface Si atoms with residual oxygen in the vacuum chamber due to SR irradiation. The oxidized Si layer was deoxidized by additional exposure to soft $\mathrm{X}$-rays. On the other hand, the SR exposure did not change the positions of the absorption edge and the white line. Therefore, the chemical environment around the Si atoms in the hydrogenated Si-DLC film was not changed by the SR irradiation. 


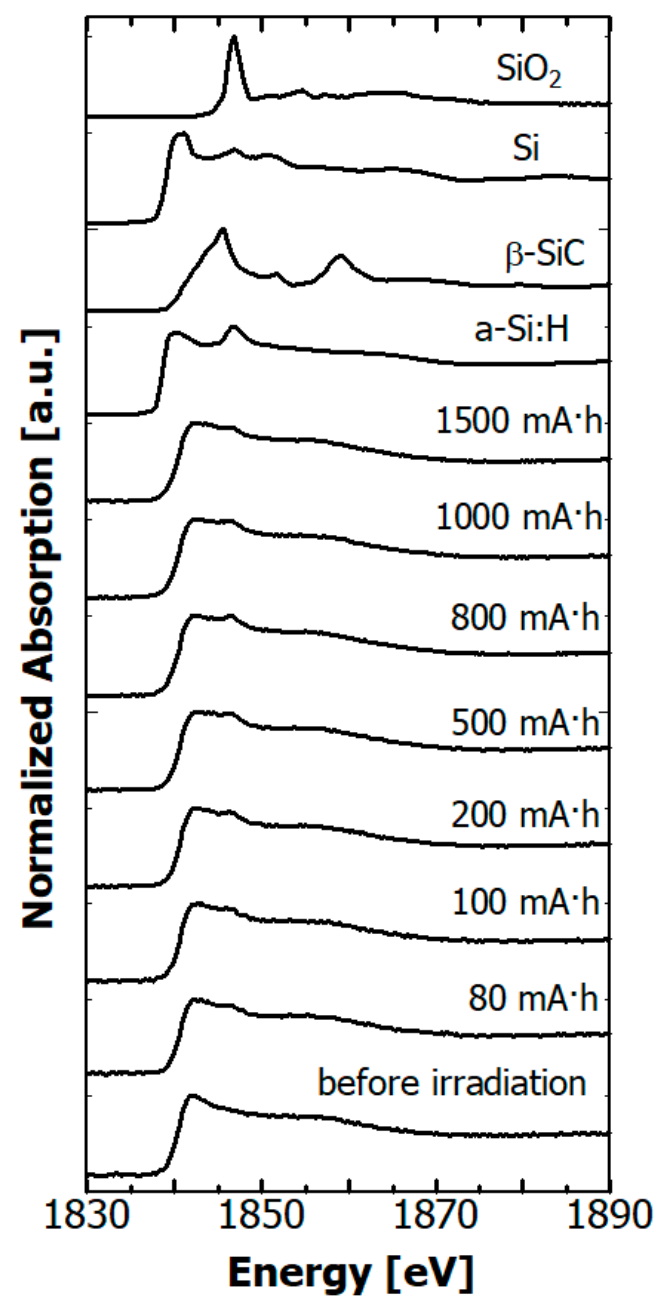

Figure 11. Dependence of Si K edge NEXAFS spectra of hydrogenated Si-DLC films on SR dose, together with those of $\mathrm{SiO}_{2}$ powder, $\mathrm{Si}$ wafer, $\beta$-SiC powder, and a-Si:H film.

The Si- $L$ edge NEXAFS spectra of the hydrogenated Si-DLC film before and after irradiation are depicted in Figure 12 together with those of $\mathrm{SiO}_{2}$ powder, $\mathrm{Si}$ wafer, a-Si:H film, and $\beta$-SiC powder. In the spectra of the $\mathrm{Si}$ wafer and a-Si:H film, peaks derived from $\mathrm{SiO}_{2}$ due to native oxidation were observed at $106 \mathrm{eV}$ [44]. In the range of 0-800 $\mathrm{mA} \cdot \mathrm{h}$, the intensity of the peak arising from $\mathrm{SiO}_{2}$ increased, while it decreased at doses greater than $1000 \mathrm{~mA} \cdot \mathrm{h}$, as in the Si K edge spectra. 


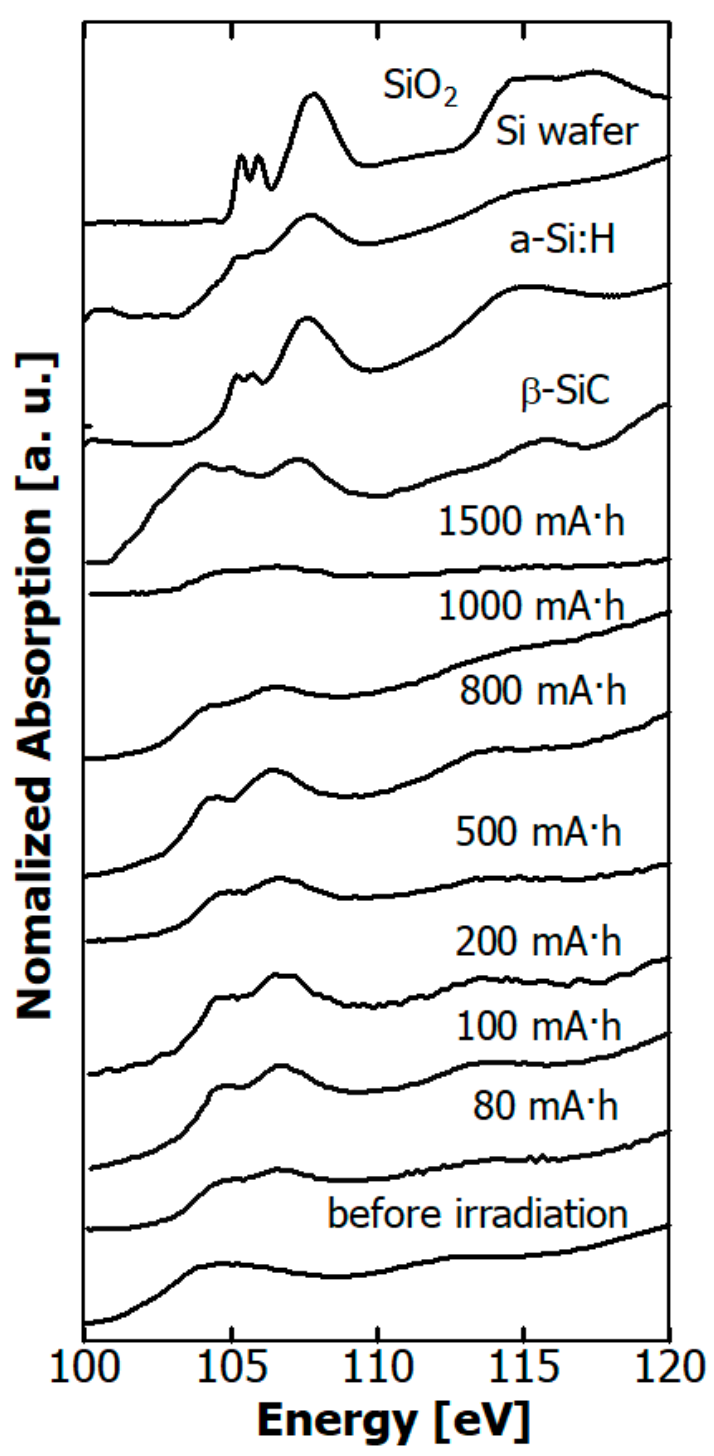

Figure 12. Dependence of Si $L$ edge NEXAFS spectra of hydrogenated Si-DLC films on SR dose, together those of $\mathrm{SiO}_{2}$ powder, $\mathrm{Si}$ wafer, a-Si:H film, and $\beta-\mathrm{SiC}$ powder.

\section{Discussion}

The effect of soft X-rays irradiating hydrogenated Si-DLC films was investigated for dose ranges up to $3000 \mathrm{~mA} \cdot \mathrm{h}$. The thickness (film volume) of hydrogenated Si-DLC film reduced after the exposure to continuous soft $\mathrm{X}$-rays up to $1000 \mathrm{eV}$. However, the rate of reduction in film thickness of the hydrogenated Si-DLC film was much lower than that of the H-DLC film. The density of the hydrogenated Si-DLC film rose a little as a result of the exposure to soft $\mathrm{X}$-rays. The elemental composition $(\mathrm{H}, \mathrm{C}$, and $\mathrm{Si})$ of the hydrogenated Si-DLC film, which was estimated from the ERDA/RBS study, did not significantly change as a result of the exposure. In addition, no significant change occurred in the surface elemental composition ( $\mathrm{C}, \mathrm{Si}$, and $\mathrm{O}$ ) in the XPS measurement. On the other hand, C K edge NEXAFS measurements showed that soft $X$-ray exposure significantly changed the local structure of the $C$ atoms, while the $\mathrm{Si} K$ edge and $\mathrm{Si} L$ edge NEXAFS measurements showed no significance.

From these experimental results, the reason why the rate of decrease in film thickness of hydrogenated Si-DLC film is much smaller than that of H-DLC film is ascribable to the process of the reduction in film thickness. The dominant process in the exposure of H-DLC film to the soft X-rays is shrinkage of the film by desorption of hydrogen from inside the film. These changes in the C-K edge NEXAFS spectra are believed to correspond 
to hydrogen desorption from the film. As described in Reference [21], hydrogen content in $\mathrm{H}$-DLC films decreases from $\sim 50 \%$ to $\sim 30 \%$ due to $200 \mathrm{~mA} \cdot \mathrm{h}$ SR exposure. On the other hand, in the exposure of the hydrogenated Si-DLC film to soft X-rays, hydrogen does not desorb from the interior of the film. In this case, the dominant process of the decrease in thickness is photoetching, which is much slower than the shrinkage due to desorption of hydrogen. This photoetching process is not one in which the activation energy determines the reaction rate, because the rate of decrease in film thickness does not change when the substrate temperature rises. In other words, this photoetching does not proceed through a temperature rise in a local area due to exposure to SR, but rather through direct inner shell excitation of the $\mathrm{C}$ and $\mathrm{Si}$ atoms in the hydrogenated Si-DLC film by the soft X-rays.

Soft $\mathrm{X}$-rays caused reactions several $\mathrm{nm}$ from the surface of the hydrogenated $\mathrm{Si}$ DLC film. In the C K edge NEXAFS spectra, the intensity of the $1 \mathrm{~s} \rightarrow \pi^{*}$ transitions at $285.4 \mathrm{eV}$ increased and the peak of the $1 \mathrm{~s} \rightarrow \sigma^{*}$ transition shifted with increasing SR dose to the high energy side in the dose range less than $20 \mathrm{~mA} \cdot \mathrm{h}$. The shift of the peak of $1 \mathrm{~s} \rightarrow \sigma^{*}$ transition was ascribable to the reduction in C atoms coupling with $\mathrm{Si}$ and $\mathrm{H}$ atoms. The peak of C-Si was observed at $\sim 287 \mathrm{eV}$ [47], and the peak at $287.8 \mathrm{eV}$ was assigned to the $1 \mathrm{~s} \rightarrow \sigma^{*}(\mathrm{C}-\mathrm{H})$ transition $[33,38]$. Therefore, the $\mathrm{C}-\mathrm{Si}$ and $\mathrm{C}-\mathrm{H}$ bonds at the surface of the hydrogenated Si-DLC films decreased as a result of soft $\mathrm{X}$-ray exposure. The $\mathrm{sp}^{2} /\left(\mathrm{sp}^{2}+\mathrm{sp}^{3}\right)$ ratio of the $C$ atoms increased from 0.23 to 0.5 in the dose range up to $20 \mathrm{~mA} \cdot \mathrm{h}$. An increase in the $\mathrm{sp}^{2} /\left(\mathrm{sp}^{2}+\mathrm{sp}^{3}\right)$ ratio due to irradiation by soft X-rays was also observed in the irradiated H-DLC film, and this increase was concluded to occur through formation of $\mathrm{C}-\mathrm{C}$ double bonds induced by the coupling between $\mathrm{C}$ atoms through desorption of hydrogen [22]. The change in the $\mathrm{sp}^{2} /\left(\mathrm{sp}^{2}+\mathrm{sp}^{3}\right)$ ratio of $C$ atoms is caused by irradiation of the hydrogenated Si-DLC film is considered to be due to the same process as in the irradiation of the H-DLC film. The structural change affecting the $\mathrm{C}$ atoms occurs only in a very thin surface layer of the hydrogenated Si-DLC film, because the rate of increase in the $\mathrm{sp}^{2} /\left(\mathrm{sp}^{2}+\mathrm{sp}^{3}\right)$ ratio ceased for SR doses greater than $20 \mathrm{~mA} \cdot \mathrm{h}$.

$\mathrm{O}$ atoms existed on the surface of the hydrogenated Si-DLC film before it was exposed to soft $\mathrm{X}$-rays. The $\mathrm{O}$ atoms adsorbed to the surface of the films during storage in the atmosphere rather than during the film deposition, because the ERDA study did not show any $\mathrm{O}$ atoms inside the film. The peak of the $\mathrm{Si}$ coupling with $\mathrm{O}$ atoms was observed in both the Si K edge and $L$ edge NEXAFS spectra after the films were exposed to soft $\mathrm{X}$-rays. On the other hand, the peak of the $\mathrm{C}$ atoms neighboring $\mathrm{O}$ atoms at $288.8 \mathrm{eV}$, which was assigned to the $1 \mathrm{~s} \rightarrow \pi^{*}$ (carboxyl group) [48], did not appear in the C K edge NEXAFS spectra. This peak was observed in spectra of surface oxidized DLC film [49]. Therefore, $\mathrm{O}$ atoms are more likely to couple with $\mathrm{Si}$ atoms than $\mathrm{C}$ atoms. Irradiation by soft $\mathrm{X}$-rays caused the $\mathrm{O}$ adhering to the surface to combine with $\mathrm{Si}$, but further irradiation caused de-oxidation.

As described above, it was found that the volume change of the hydrogenated DLC film due to soft X-ray irradiation was suppressed by silicon doping into film. This is attributed to the suppression of hydrogen desorption from the film. We believe that the mechanism of the suppression of hydrogen desorption by silicon doping may be as follows: (1) Si atoms on the surface of the hydrogenated Si-DLC film are spontaneously oxidized to silicon oxide, which suppresses hydrogen desorption from inside the film; (2) Soft X-ray irradiation desorbs hydrogen from the film near the surface, increasing the concentration of Si atoms in the surface vicinity, which oxidizes in the same way as in (1), and the silicon oxide layer suppresses hydrogen desorption; and (3) Soft X-ray irradiation desorbs hydrogen from the film near the surface, forming the C-Si network in the surface vicinity, which suppresses hydrogen desorption. We are planning to conduct experiments to test these hypotheses.

\section{Conclusions}

The effect of SR on the hydrogenated Si-DLC film was investigated by continuous soft X-ray irradiation at less than $1000 \mathrm{eV}$, which is an important environmental factor in LEO. 
The dependences of the volume, elemental composition, and local structure of $\mathrm{C}$ and $\mathrm{Si}$ atoms on the SR dose were measured in a dose range up to $3000 \mathrm{~mA} \cdot \mathrm{h}$. The reduction in volume of the H-DLC film by the exposure to soft X-rays was due to the bonds between $\mathrm{C}$ and $\mathrm{H}$ being broken and hydrogen being desorbed, with the remaining $\mathrm{C}$ being combined with other C atoms in the DLC film. These processes could be suppressed by doping the film with $\mathrm{Si}$. The dominant process affecting the volume reduction of the hydrogenated Si-DLC film due to the exposure to soft X-rays was photoetching and the rate of reduction was 80 times slower than that of the H-DLC film. The irradiated film was modified only within the vicinity (several $\mathrm{nm}$ ) of the surface. In addition, it was observed that $\mathrm{Si}$ and absorbed $\mathrm{O}$ were combined due to exposure to soft $\mathrm{X}$-rays and separated due to excessive soft X-ray irradiation in most surface.

H-DLC films have a low coefficient of friction in vacuum, but their lifetime is short due to desorption of hydrogen during friction. The results of this study indicate the possibility of retaining $\mathrm{H}$ in the film by reacting with Si present in the film, which is expected to extend the life of H-DLC film. Further investigations will be needed before hydrogenated Si-DLC films can be used on LEO satellites. We are planning to perform experiments on (1) the dependence of film durability against $X$-rays versus $\mathrm{Si}$ content of the film; (2) simultaneous irradiation of samples with $\mathrm{X}$-rays and $\mathrm{AO}$; and (3) lubricant performance.

Author Contributions: Conceptualization, K.K.; methodology, M.N., T.H., T.S., and H.A.; validation, R.I., S.T., S.S. and M.N. investigation, R.I., S.T., S.S., and M.N.; writing-original draft preparation, S.T.; writing-review and editing, K.K.; visualization-S.T., S.S. and M.N.; supervision, K.K. All authors have read and agreed to the published version of the manuscript.

Funding: This research was funded by JSPS KAKENHI, Grant No. JP17K06799, and a Research Grant from the Nippon Sheet Glass Foundation for Materials Science and Engineering.

Institutional Review Board Statement: Not applicable.

Informed Consent Statement: Not applicable.

Data Availability Statement: Data sharing not applicable.

Acknowledgments: The authors would like to thank Akira Heya of the University of Hyogo for providing the a-Si:H film used as a reference material. We also thank the NewSUBARU staff for their efforts to ensure stable operation of the NewSUBARU ring.

Conflicts of Interest: The authors declare no conflict of interest.

\section{References}

1. Aisenberg, S.; Chabot, R. Ion-Beam Deposition of Thin Films of Diamondlike Carbon. J. Appl. Phys. 1971, 42, $2953-2958$. [CrossRef]

2. Robertson, J. Properties of diamond-like carbon. Surf. Coat. Technol. 1992, 50, 185-203. [CrossRef]

3. Robertson, J. Diamond-like amorphous carbon. Mater. Sci. Eng. R Rep. 2002, 37, 129-281. [CrossRef]

4. Aisenberg, S. Properties and applications of diamondlike carbon films. J. Vac. Sci. Technol. A 1984, 2, 369-371. [CrossRef]

5. Gupta, B.; Bhushan, B. Micromechanical properties of amorphous carbon coatings deposited by different deposition techniques. Thin Solid Films 1995, 270, 391-398. [CrossRef]

6. Grill, A. Diamond-like carbon: State of the art. Diam. Relat. Mater. 1999, 8, 428-434. [CrossRef]

7. Erdemir, A.; Donnet, C. Tribology of diamond-like carbon films: Recent progress and future prospects. J. Phys. D Appl. Phys. 2006, 39, R311-R327. [CrossRef]

8. Ohgoe, Y.; Hirakuri, K.; Saitoh, H.; Nakahigashi, T.; Ohtake, N.; Hirata, A.; Kanda, K.; Hiratsuka, M.; Fukuia, Y. Classi-fication of DLC films in terms of biological response. Surf. Coat. Technol. 2012, 207, 350-354. [CrossRef]

9. Nakamura, T.; Ohana, T. Photochemical modification of DLC films with oxygen functionalities and their chemical structure control. Diam. Relat. Mater. 2013, 33, 16-19. [CrossRef]

10. Neuville, S. New application perspective for tetrahedral amorphous carbon coatings. QScience Connect 2014, 8, 1-27. [CrossRef]

11. Baba, K.; Hatada, R. Deposition and characterization of Ti- and W-containing diamond-like carbon films by plasma source ion implantation. Surf. Coat. Technol. 2003, 2003, 287-290. [CrossRef]

12. Cui, L.; Guoqing, L.; Wenwu, C.; Zongxin, M.; Chengwu, Z.; Liang, W. The study of doped DLC films by Ti ion implan-tation. Thin Solid Films 2005, 475, 279-282. [CrossRef] 
13. Ouyang, J.-H.; Sasaki, S. Friction and wear characteristics of a Ti-containing diamond-like carbon coating with an SRV tester at high contact load and elevated temperature. Surf. Coat. Technol. 2005, 195, 234-244. [CrossRef]

14. Lubwama, M.; Corcoran, B.; McDonnell, K.; Dowling, D.; Kirabira, J.; Sebbit, A.; Sayers, K. Flexibility and frictional behaviour of DLC and Si-DLC films deposited on nitrile rubber. Surf. Coat. Technol. 2014, 239, 84-94. [CrossRef]

15. Kidena, K.; Endo, M.; Takamatsu, H.; Niibe, M.; Tagawa, M.; Yokota, K.; Furuyama, Y.; Komatsu, K.; Saitoh, H.; Kanda, K. Resistance of Hydrogenated Titanium-Doped Diamond-Like Carbon Film to Hyperthermal Atomic Oxygen. Metals 2015, 5, 1957-1970. [CrossRef]

16. Wang, J.; Ma, J.; Huang, W.; Wang, L.; He, H.; Liu, C. The investigation of the structures and tribological properties of F-DLC coatings deposited on Ti-6Al-4V alloys. Surf. Coat. Technol. 2017, 316, 22-29. [CrossRef]

17. Donnet, C.; Belin, M.; Augé, J.; Martín, J.; Grill, A.; Patel, V. Tribochemistry of diamond-like carbon coatings in various environments. Surf. Coat. Technol. 1994, 1994, 626-631. [CrossRef]

18. Donnet, C.; Fontaine, J.; Le Mogne, T.; Belin, M.; Héau, C.; Terrat, J.; Vaux, F.; Pont, G. Diamond-like carbon-based functionally gradient coatings for space tribology. Surf. Coat. Technol. 1999, 120, 548-554. [CrossRef]

19. Donnet, C.; Erdemir, A. Tribology of Diamond-Like Carbon; Springer: Boston, MA, USA, 2008.

20. Kyuragi, H.; Urisu, T. Synchrotron radiation-induced etching of a carbon film in an oxygen gas. Appl. Phys. Lett. 1987, 50, 1254-1256. [CrossRef]

21. Kanda, K.; Yokota, K.; Tagawa, M.; Tode, M.; Teraoka, Y.; Matsui, S. Effect of the Soft X-rays on Highly Hydrogenated DiamondLike Carbon Films. Jpn. J. Appl. Phys. 2011, 50, 055801. [CrossRef]

22. Kanda, K.; Imai, R.; Niibe, M.; Yoshioka, H.; Komatsu, K.; Saitoh, H. Modification Processes of Highly Hydrogenated DiamondLike Carbon Thin Films by Soft X-ray Irradiation. Sensor Mater. 2017, 29, 817-826.

23. Nakahigashi, T.; Tanaka, Y.; Miyake, K.; Oohara, H. Properties of flexible DLC film deposited by amplitude-modulated RE P-CVD. Triol. Int. 2004, 37, 907-912. [CrossRef]

24. Ando, A.; Amano, S.; Hashimoto, S.; Kinosita, H.; Miyamoto, S.; Mochizuki, T.; Niibe, M.; Shoji, Y.; Terasawa, M.; Watanabe, T. VUV and soft X-ray light source "New SUBARU". In Proceedings of the 1997 Particle Accelerator Conference (Cat. No.97CH36167), Vancouver, BC, Canada, 16 May 1997; 1997; Volume 1, pp. 757-759.

25. Hashimoto, S.; Ando, A.; Amano, S.; Haruyama, Y.; Hattori, T.; Kanda, K.; Kinoshita, H.; Matsui, S.; Mekaru, H.; Miyamoto, S.; et al. Present Status of Synchrotron Radiation Facility “NewSUBARU”. Trans. Mat. Res. Soc. Japan 2001, 26, 783-786.

26. Kanda, K.; Ideta, T.; Haruyama, Y.; Ishigaki, H.; Matsui, S. Surface Modification of Fluorocarbon Polymers by Synchrotron Radiation. Jpn. J. Appl. Phys. 2003, 42, 3983-3985. [CrossRef]

27. Kato, Y.; Kanda, K.; Haruyama, Y.; Matsui, S. Synchrotron Radiation Effect in the Soft X-ray Region on the Surface Prop-erties of Pyromellitic Dianhydride-Oxydianline Polyimide. Jpn. J. Appl. Phys. 2004, 43, 3938-3940. [CrossRef]

28. Ohkawara, Y.; Ohshio, S.; Suzuki, T.; Ito, H.; Yatsui, K.; Saitoh, H. Quantitative Analysis of Hydrogen in Amorphous Films of Hydrogenated Carbon Nitride. Jpn. J. Appl. Phys. 2001, 40, 7007-7012. [CrossRef]

29. Ohkawara, Y.; Ohshio, S.; Suzuki, T.; Ito, H.; Yatsui, K.; Saitoh, H. Dehydrogenation of Nitrogen-Containing Carbon Films by High-Energy He2+Irradiation. Jpn. J. Appl. Phys. 2001, 40, 3359-3363. [CrossRef]

30. Igaki, J.-Y.; Saikubo, A.; Kometani, R.; Kanda, K.; Suzuki, T.; Niihara, K.; Matsui, S. Elementary Analysis of Diamond-Like Carbon Film Formed by Focused-Ion-Beam Chemical Vapor Deposition. Jpn. J. Appl. Phys. 2007, 46, 8003-8004. [CrossRef]

31. Kanda, K.; Okada, M.; Kang, Y.; Niibe, M.; Wada, A.; Ito, H.; Suzuki, T.; Matsui, S. Structural Changes in Diamond-Like Carbon Films Fabricated by Ga Focused-Ion-Beam-Assisted Deposition Caused by Annealing. Jpn. J. Appl. Phys. 2010, 49, 06 GH06. [CrossRef]

32. Fuggle, J.C.; Inglesfield, J.E. Unoccupied Electronic States; Springer: Berlin/Heidelberg, Germany, 1992.

33. Stöhr, J. NEXAFS Spectroscopy; Springer International Publishing: New York City, NY, USA, 1992.

34. Niibe, M.; Mukai, M.; Kimura, H.; Shoji, Y. Polarization Property Measurement of the Long Undulator Radiation Using Cr/C Multilayer Polarization Elements. Fourth Huntsville Gamma-Ray Burst Symp. 2004, 705, 243-246. [CrossRef]

35. Niibe, M.; Mukai, M.; Miyamoto, S.; Shoji, Y.; Hashimoto, S.; Ando, A.; Tanaka, T.; Miyai, M.; Kitamura, H. Characterization Of Light Radiated From 11 m Long Undulator. Fourth Huntsville Gamma-Ray Burst Symp. 2004, 705, 576. [CrossRef]

36. Kanda, K.; Hasegawa, T.; Uemura, M.; Niibe, M.; Haruyama, Y.; Motoyama, M.; Amemiya, K.; Fukushima, S.; Ohta, T. Construction of a wide-range high-resolution beamline BL05 in NewSUBARU for X-ray spectroscopic analysis on in-dustrial materials. J. Phys. Conf. Ser. 2013, 425, 132005. [CrossRef]

37. Niibe, M.; Kotaka, T.; Mitamura, T. Investigation of analyzing depth of N-K absorption spectra measured using TEY and TFY methods. J. Phys. Conf. Ser. 2013, 425, 132008. [CrossRef]

38. Lenardi, C.; Piseri, P.; Briois, V.; Bottani, C.E.; Bassi, A.L.; Milani, P. Near-edge x-ray absorption fine structure and Raman characterization of amorphous and nanostructured carbon films. J. Appl. Phys. 1999, 85, 7159-7167. [CrossRef]

39. Kanda, K.; Niibe, M.; Wada, A.; Ito, H.; Suzuki, T.; Ohana, T.; Ohtake, N.; Saitoh, H. Comprehensive Classification of Near-Edge X-ray Absorption Fine Structure Spectra of Si-Containing Diamond-Like Carbon Thin Films. Jpn. J. Appl. Phys. 2013, 52, 95504. [CrossRef]

40. Ferrari, A.C.; Robertson, J. Interpretation of Raman spectra of disordered and amorphous carbon. Phys. Rev. B 2000, 61, 14095-14107. [CrossRef] 
41. Kanda, K.; Kitagawa, T.; Shimizugawa, Y.; Haruyama, Y.; Matsui, S.; Terasawa, M.; Tsubakino, H.; Yamada, I.; Gejo, T.; Kamada, M. Characterization of hard DLC films formed by Ar gas cluster ion beam-assisted fullerene deposition. Jpn. J. Appl. Phys. 2002, 41, 4295-4298. [CrossRef]

42. Saikubo, A.; Kanda, K.; Niibe, M.; Matsui, S. Near-edge X-ray absorption fine-structure characterization of diamond-like carbon thin films formed by various method. New Diam. Front. Carbon Technol. 2006, 16, 235-244.

43. Saikubo, A.; Yamada, N.; Kanda, K.; Matsui, S.; Suzuki, T.; Niihara, K.; Saitoh, H. Comprehensive classification of DLC films formed by various methods using NEXAFS measurement. Diam. Relat. Mater. 2008, 17, 1743-1745. [CrossRef]

44. Li, D.; Bancroft, G.M.; Kasrai, M.; Fleet, M.E.; Secco, R.A.; Feng, X.H.; Tan, K.H.; Yang, B.X. X-ray absorption spectroscopy of silicon dioxide (SiO2) polymorphs: The structural characterization of opal. Am. Miner. 1994, 79, 622-632.

45. Sammynaiken, R.; Naftel, S.; Sham, T.K.; Cheah, K.W.; Averboukh, B.; Huber, R.; Shen, Y.R.; Qin, G.G.; Ma, Z.C.; Zong, W.H. Structure and electronic properties of $\mathrm{SiO}_{2} / \mathrm{Si}$ multilayer superlattices: $\mathrm{Si} \mathrm{K}$ edge and $\mathrm{L}_{3,2}$ edge X-ray absorption fine structure study. J. Appl. Phys. 2002, 92, 3000-3006. [CrossRef]

46. Kanda, K.; Suzuki, S.; Niibe, M.; Hasegawa, T.; Suzuki, T.; Saitoh, H. Local Structure Analysis on Si-Containing DLC Films Based on the Measurement of C K-Edge and Si K-Edge X-ray Absorption Spectra. Coatings 2020, 10, 330. [CrossRef]

47. Jung, H.-S.; Park, H.-H.; Mendieta, I.R.; Smith, D.A. Determination of bonding structure of Si, Ge, and N incorporated amorphous carbon films by near-edge x-ray absorption fine structure and ultraviolet Raman spectroscopy. J. Appl. Phys. 2004, 96, 1013-1018. [CrossRef]

48. Jaouen, M.; Tourillon, G.; Delafond, J.; Junqua, N.; Hug, G. A NEXAFS characterization of ion-beam-assisted car-bon-sputtered thin films. Diam. Relat. Mater. 1995, 4, 200-206. [CrossRef]

49. Tagawa, M.; Yokota, K.; Kitamura, A.; Matsumoto, K.; Yoshigoe, A.; Teraoka, Y.; Kanda, K.; Niibe, M. Synchrotron radiation photoelectron spectroscopy and near-edge X-ray absorption fine structure study on oxidative etching of diamond-like carbon films by hyperthermal atomic oxygen. Appl. Surf. Sci. 2010, 256, 7678-7683. [CrossRef] 